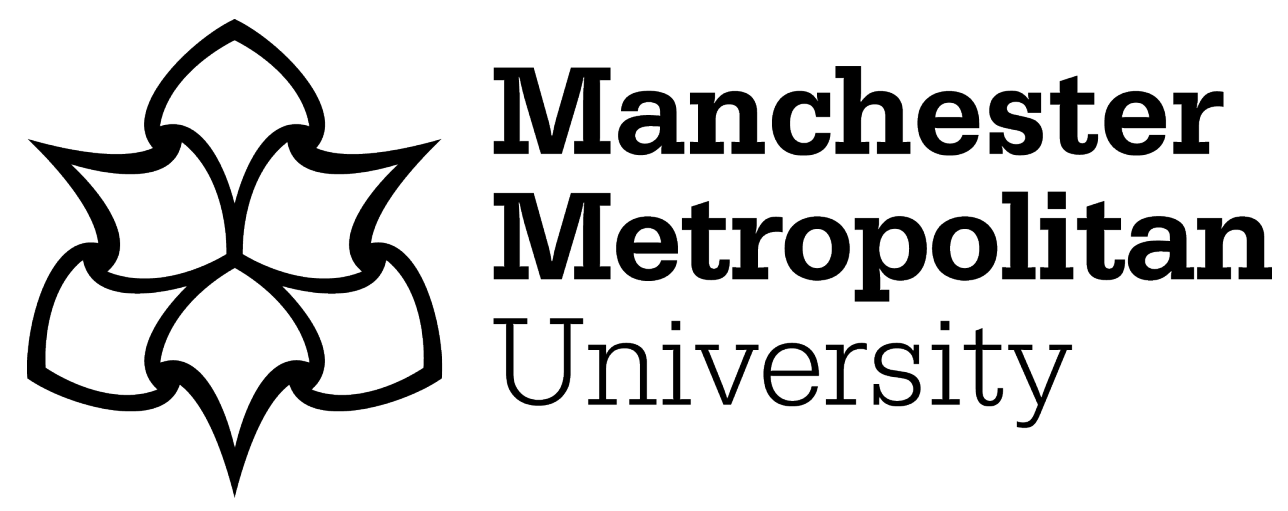

Popan, Cosmin (2020) Beyond utilitarian mobilities: cycling senses and the subversion of the car system. Applied Mobilities, 5 (3). pp. 289-305. ISSN 2380-0127

Downloaded from: https://e-space.mmu.ac.uk/627085/

Version: Accepted Version

Publisher: Informa UK Limited

DOI: https://doi.org/10.1080/23800127.2020.1775942

Please cite the published version 


\title{
Beyond utilitarian mobilities: cycling senses and the subversion of the car system
}

\author{
Cosmin Popan
}

Department of Sociology, Manchester Metropolitan University, Manchester, UK

\begin{abstract}
Increasing concerns regarding congestion, pollution and health have warranted a renewed interest in cycling as alternative mobility. Yet, in revising the role of the bicycle as legitimate transportation, policy documents and academic literature have paid less attention to how cycling is different from the sensory engagement through the car, public transport, or walking. This article uses sensuous and video ethnographies of cycling in London and Lancaster (UK) to present cycling as a distinctly embodied practice. By investigating the cycling senses and how its technologies and materialities shape the mobile experience, the article contributes to the critiques of urban movement narrowly understood as utilitarian and instrumental. At a time when transition to low-carbon transport systems is critical and when automated driving futures appear imminent, this article argues for the pervasive centrality of the body in everyday urban mobilities.
\end{abstract}

\section{ARTICLE HISTORY}

Received 7 May 2019

Accepted 27 May 2020

\section{KEYWORDS}

Cycling; mobilities; senses; sensuous ethnography; video ethnography

\section{Introduction}

In recent years, cycling has drawn a remarkable amount of policy and public attention. Amongst the most significant recent policy publications are the UK's "Cycling and Walking Investment Strategy" (Department for Transport 2017), the World Health Organisation's "Health economic assessment tool for cycling and walking" (WHO 2017) or the proposed EU Cycling Strategy (ECF 2017). What used to be up until the last few decades a marginalised domain, pursued by advocacy and lobbying groups such as the European Cyclists' Federation, Sustrans or Cycling UK, has gradually gained attention in the public sphere through media and public events. ${ }^{1}$ Overall, the recent focus of policy and public concern on cycling has centred on the health and economic dimensions of the practice. This interest in the more quantifiable aspects of cycling has overshadowed the mundane, everyday experience of self-propelled mobility on two (or more) wheels.

As the "new mobilities paradigm" in the social sciences suggests, there is value to the embodied nature and experience of all mobilities, including cycling, as "time spent travelling is not dead time that people seek to minimise" (Sheller and Urry 2006, 213). In developing a politics of mobility, Cresswell also argues that mobility can be conceptualised as "an entanglement of movement, representation, and practice" $(2010,17)$. Transport researchers, he says, "have developed ways of telling us about the fact of 
movement, how often it happens, at what speeds, and where", but they have been less successful at "telling us about the representations and meanings of mobility" $(2010,19)$. The majority of policy documentation on cycling is thus limited to discussing the modal share of cycling trips in the total traffic volume (Transport for London 2008), the amount of time that cycling is saving commuters at peak hours (Transport for London 2013), its contribution to the UK economy (Grous 2011), or the money saved by the National Health Service as a result of the healthy lifestyles of those who cycle (Jarrett et al. 2012). But, as Cresswell points out, our everyday movement in the city represents an "embodied practice that we experience in ways that are not wholly accounted for by either their objective dimensions or their social and cultural dimensions" $(2010,20)$.

Some of the academic literature in the fields of sociology, anthropology and human geography has started to address the embodied nature of everyday urban mobilities. Walking, which has a longstanding tradition in enabling a sociological "reading" of the city (de Certeau 1984; Debord 1959; Jacobs 1961; Sennett 2008, 1992), has more recently drawn attention of academia, but the general focus remains on leisure practices (Edensor 2000; Ingold 2004). Much of this research sees walking "as self-evident and instrumental whilst neglecting the actual experiences of urban pedestrians and the multiplicity associated with those experiences" (Middleton 2010). More recently, commuter running has also been explored from a sensory perspective. According to Cook, Shaw, and Simpson (2016), the senses "are essential to accomplishing a run by, among other things, gauging ability, judging proximity, calculating safety, recognising terrain and assessing pace toleration, particularly when running with somebody else" $(2016,750)$. Skateboarding, another intensive and similarly marginal form of urban mobility, has been investigated by Borden (2001), who describes it as "a physical activity, undertaken against the materiality of the modern city" $(2001,171)$ and who advanced a relational understanding of architecture as an ongoing process constructed by space, time and social beings.

Driven by the uptake in cycling in many urban environments, the last decade has generated similar research interests in relation to cycling. It has been argued that a sensorial investigation of cycling has the capacity to demonstrate the limitations of a research agenda conceiving mobilities as rationalised and instrumental (Spinney 2009). By focusing on its embodied nature, cycling research could "illuminate the complexity and breadth of meaning inherent in a practice", while highlighting "the importance of technology, the body, and space in producing styles of mobility" $(2009,818)$. Consequently, more current academic explorations of the sensory engagements by bicycle have unveiled the multitude of meanings associated with the practice.

Spinney (2006) has looked at how the embodied rhythms and kinaesthetic sensations of the movement of cycling are mobilised to explain how sport cyclists find meaning through pain. Jones (2012) further shows how the embodied experience of cycling challenges the dominant sensory discipline characterising contemporary Western cultures of mobility: "commuter cycling makes intense demands on the affective capacity of its participants, producing a rich, though not necessarily positive, sensescape at the porous boundary between body and world" $(2012,655)$. Simpson $(2017)$ has also emphasised the role of transport infrastructures and road materialities in affording a certain cycling "atmosphere", which, similarly, can be positive or negative: "These infrastructuremediated interactions can be more or less convivial, more or less constraining-enabling, in terms of how these interactions unfold and these affects circulate" $(2017,4)$. 
This paper proposes a comprehensive approach to the sensory experience of cycling. While the aforementioned authors all address the embodied nature of cycling and other mobility practices, their account of the senses is often limited to how they orient the subjects in the social and material world. They focus less on the specific performance of cyclists' senses and on their complementary work to engage the whole body with the urban environment. Beyond the mobilities and cycling scholarship, there already exists a relatively strong literature and set of discussions on proprioception and the need to extend the five senses model (Pink 2009; Featherstone 2010). Through this paper, I show how cycling offers a good example to bolster this existing critique of the culturally constructed five senses approach to perception.

\section{Methods}

Following the invitation from the field of mobility studies to devise "an array of methods that in different ways capture, track, simulate, mimic, parallel and 'go along with' the kinds of moving systems and experiences that seem to characterise the contemporary world" (Büscher et al. 2011, 7), most recent cycling research has used "ride alongs" and video footage to investigate the practice (Aldred and Jungnickel 2012; Larsen 2014; Spinney 2009). But while replaying the video footage of a ride with participants allows indeed a "very nuanced account of place and the body to emerge" (Spinney 2011, 168), the multitude of senses which are involved in cycling are still difficult to capture. Descriptions of sensations relating to pain, temperature of the body and the environment, the internal struggle of muscles and organs are enriched when using video as a prompt for riders to remember and translate into words the embodied experiences. But the moment of the actual movement has already long passed, thus making the effort of recollecting memory a challenging one.

An alternative and complementary approach is to engage the researcher's own body in the process of data collection. Auto-ethnography is particularly useful as "a means of getting across intangible and complex feelings and experiences that somehow can't be told in conventional ways" (Muncey 2010, 1). In cycling research, auto-ethnography has already been used to illuminate the embodied qualities of movement (Jones 2005; Larsen 2014; Spinney 2006, 2007) and has involved various strategies, ranging from "ethnographic fiction" blending a researcher's own experience with other cyclists' narratives (Spinney 2007), to "vignettes" used to describe the embodied process of becoming a long-distance commuter cyclist (Larsen 2014), to "performances" that highlight the physicality of cycling and its remaking of the city (Jones 2005).

For this research, auto-ethnography involved three types of data collection. Firstly, it engaged my own cycling, unfolding in two different environments: the traffic-choked commute at rush hour in Central London, from Aldgate to Saint Pancras (5.6 km, on a flat route), and partly traffic-free commute in Lancaster, from the centre to the university campus outside the city ( $5.7 \mathrm{~km}$, on a hilly route). The shared-use routes for pedestrians and cyclists, more common during the commute in Lancaster, favoured slower cycling and allowed a better focus on the immediate sensations of the ride. During these pleasant rides, it was easier to focus and reflect on less perceptible senses such as balance, movement and temperature. On the contrary, the research site in London coerces cyclists to ride faster and to mix with the busy car traffic and demands an increased awareness of 
the road environment. These rides were certainly more laborious and tiring, requiring more attention to the road dangers, particularly for vision and hearing. Between October 2014 and March 2016, I commuted regularly by bicycle in London and Lancaster. An average of two and five weekly rides, back and forth, were undertaken in London and Lancaster, respectively.

Secondly, some of the rides involved video footage, recorded with a GoPro camera. The front-facing camera mounted on top of the head (or the bicycle helmet), at around $10 \mathrm{~cm}$ above the eyes, took an almost "point of view shot". Albeit making objects at the periphery of the visual field seem closer than they are, the wide camera angle of the GoPro further extended the capabilities of the eyes, bringing to attention details that were beyond the immediate perception of the researcher. In other circumstances, the camera was directed towards the ground, recording my pedalling and thus highlighting senses such as kinaesthesia and balance.

The video camera has nevertheless obvious limitations with regards to eliciting the multisensory aspects of cycling. Thus, I have used the video footage mainly as a complement to other methods, upon which a richer description of these senses was consequently built. Helmet-mounted camera can trigger different reactions from other road users and potentially impact upon one's sensory engagement with the mobile environment: anecdotal evidence reported in the media suggests that many drivers are annoyed by cyclists who wear such devices to record careless or dangerous driving (Vine 2015; Hopkins 2015). Fifteen rides were video-recorded, in both London and Lancaster. The footage was replayed during the field notes transcription to complement the immediate recollection of the cycling experience.

Finally, audio descriptions of the cycling experience were added to generate an extra layer of information to those provided by video camera. I used a headset microphone connected to a voice recorder onto which I dictated an account of the sensations experienced on the move. This real-time audio diary complements the video recording to provide additional cues on the "voice" of the body, often materialised in heavy breathing, coughing or gasps. Most importantly, through the audio recording, I could give voice to immediate and fleeting sensations that could not be captured through the usual postride note taking or through the lens of the GoPro.

Overall, an auto-ethnographic approach to cycling senses has its own limitations. Merchant notes that "just because the researcher is engaged in the activities being studied does not mean he/she is experiencing them in the same way as others" (2011, 55). Sensorial experiences are indeed not only informed by the personal capabilities of the researcher, but also by other social and cultural backgrounds underpinning her or his identity (Popan 2019).

This paper argues that, methodologically, cycling research and the future of cycling practices and its urban nature and popularity cannot be examined outside the multiple senses involved in cycling. Following the multisensorial turn in geographic studies, which argues for a shift from the gaze to the multisensorial (Rodaway 1994; Pink 2009), this paper advocates for embodied research as a means to represent the cycling experience differently. It challenges the view reflected by most traffic modelling experts that mobility is an empty category whereby, more important than the journey itself, are the departure and destination points (Popan 2019). The future of cycling is thus not only in quantitative analysis but in high grained analysis of the meanings, competences and materialities 
(Shove, Pantzar, and Watson 2012), that can be best grasped and captured via multisensorial methodological approach.

The remainder of this paper is structured as follows. Firstly, it presents some autoethnographic data in relation to vision and hearing, drawing on field notes comprising both direct observation and information recorded with audio and video technologies. Some general points are made about the difference in seeing and hearing between cyclist and other road users, the complementarity of the two senses and how they structure cyclists' relationship with the road space. Secondly, drawing on literature from the fields of ecological psychology and anthropology of the senses, the paper argues for an understanding of cyclists' perception as multisensory. It is illustrated how the senses do not operate on their own and how they cannot be separated from one another in perception. Thirdly, following developments in the field of human geography, it is claimed that the environment where cycling unfolds is perceived through the body and the bicycle. This observation is extremely relevant in order to unpack the political and power relations affecting the cycling experience within car-dominated societies. Finally, the paper considers the sustainability of cycling in car-dominated cities. It does so by investigating its temporalities within the urban environment by focusing on the rhythms it generates and how they are sustained within the hegemonic rhythm of automobility.

\section{Velomobility at a glance}

When I cycle, I run red lights. Although I do not encourage anyone to follow my lead, I have my reasons for this: I feel safer if I have an earlier start than the cars when the lights turn green; there may be a rainy day and I am already soaked and freezing; there is a certain rhythm and sense of equilibrium I keep if I do not have to rest my feet on the ground; and most relevant here, I try to catch the eyes of the drivers and establish some visual contact, thus knowing that I am safe to go (Field notes, London, 2015).

There is a set of standard visual exchanges that all traffic participants seem to share to avoid colliding with one other and to express approval or disapproval of others' behaviours. Conley calls them types of "mobile looking" (2012). They are: "identifying scans", used to make sure others are acting "normally" or "abnormally"; "focused looks", deployed to settle on a particular element if relevant; "sanctioning looks", to get one's attention in order to convey disapproval; and, as with my case, "integrating glances", for catching another's eye to indicate a shared assessment of the situation $(2012,208)$. While these types of mobile looking might be shared by both drivers and cyclists, the differences in speed and material configuration between the two vehicles contribute to distinctive visual experiences.

The important thing about vision in cycling is its less-mediated, almost shell-less, nature. Unlike drivers and motorcyclists, cyclists do not have windscreens, visor helmets and mirrors that frame and fragment perception. The effect of light glinting on windscreens renders the driver invisible from outside, while the motor-cyclist, protected by the visor helmet, also has no human presence in traffic in the same way that the face provides. This privilege of separation is not afforded to the cyclist, for whom direct facial contact in social interaction, or "copresence" (Goffman 1963), is essential. As a result, they adopt specific strategies, ranging from mundane exchanges of glances with others ahead or 
looking back over one's own shoulder, to more complex ones such as looking ahead over another cyclist's shoulder, particularly at higher speed, or anticipating a left-turning car by checking if its front wheels are changing position. The absence of a windscreen makes it difficult to avoid exposing the eyes to various elements such as sun, rain, snow, wind, even insects. Thus, many cyclists wear sunglasses or caps with visors.

The bicycle also has a design that furthermore distinguishes the vision of cyclists. Most often one sits on a bike at a higher level than the seat of the average car, giving better vision at distance. This advantage is offset by the constraint to check the road surface more often for holes, bumps or other obstacles. But bicycles themselves are also of many kinds, with different designs and geometries. In London and Lancaster, I rode a road bike, which prioritizes efficiency over comfort and forces me into a lean-forward position where vision at a distance and peripheral vision are significantly reduced. The visual range it affords is smaller than that of the common upright bicycles used, for example, in Copenhagen or Amsterdam.

Before moving to discuss hearing, which is another important sense for cyclists' safety, two brief observations in relation to vision need to be made, which will be further explored later. First, vision does not operate in a vacuum to orient the cyclist on the road, but overlaps with one's body movement, as it happens, for example, when looking back over one's shoulder for an incoming vehicle. Vision is here better understood as "skilled visions [which] are embedded in multi-sensory practices, where look is coordinated with skilled movement, with rapidly changing points of view, or with other senses such as touch" (Grasseni 2007,4).

Second, the discussion above has also suggested that vision, alongside the other senses which will be further discussed, effectively shapes the environment where cycling unfolds. How we see the world from the bike is both a relationship to this world and a way to structure and define our perception of space and place. The less-mediated and shellness nature of cyclists' vision or the better vision at a distance when riding an upright bicycle contribute to a reconfiguration of our awareness of the cityscapes which is substantially different from that afforded to car drivers.

\section{Grow ears, awaken the whole body}

I can hear the sewerage running beneath the road. I run the red light, I keep right as I have to make a turn very soon. There are some buses in the back, I can't see them, but I hear their noise. [...] I can hear a worn-out chain on the bike in the front. He's not riding very fast, but I don't mind staying behind. I hear a motorcycle now, roaring in the back, he wants to overtake, I can't see it but I can hear it very well (Figure 1) (Field notes, London, 2015).

In an environment replete with stimuli, listening not only becomes almost as important as seeing, but, as indicated above, it fills the gaps opened by limited vision. I cannot see the vehicles approaching from behind, but I can always hear them, and this information can be critical for my safety.

"Individuals" relation to sound in the everyday spaces of the city tend to be one of the distractions rather than attention, observes Tonkiss $(2003,304)$, who insists on how ears cannot discriminate in the same way eyes can. Still, in this context, the ears pay very close attention. Aural perception is very poor at specifying direction and distance for mobile 

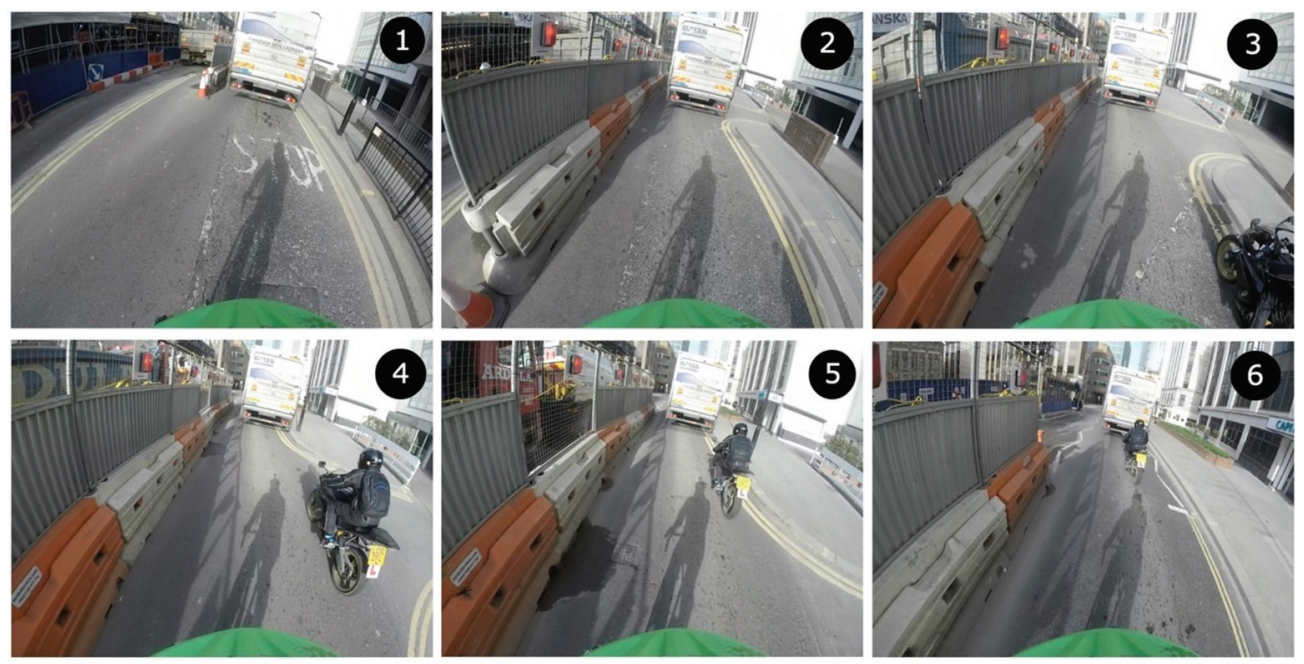

Figure 1. (from top left to bottom right): I can hear a motorcycle now roaring in the back as it wants to overtake me can't see it but I can hear it very well (London, 2015).

subjects, thus sight is so much more important for driving and cycling. Progress through space by sound alone is difficult and potentially dangerous. Yet, sound brings dangers to attention in ways the eyes do not, so one can look to fine-tune the appropriate response: steering, braking or accelerating. Moreover, if enough attention is paid, it is even possible to tell the next move of the driver behind: often a rising pitch of an engine sound indicates the car is going to overtake. A steady, low engine note means, on the other hand, that a car is "tracking" the cyclist, waiting for a good opportunity to pass.

The cyclist-bicycle hybrid is not only exposed to surrounding urban sounds but it also generates its own "acoustic territory", a "topography of auditory life" (LaBelle 2010), almost inaudible from the louder engine sound. The rhythm of cycling emerges from both body and machine, the symbiosis of which generates an enveloping sound membrane, the result of a resounding body voicing the effort through audible heartbeats and breathing, and of a machine engaged in circular movement, its scratchy tires, the snoring chain, the clicking freewheel. The sound, but also the feel of the bike, is an integrated sense of the state of the bike.

Once again, it becomes apparent how cyclists' perception involves a multisensory experience, which is not limited to one sense taking precedence over the others. The idea of a sound membrane is such an instance of hearing overlapping with touch in the act of perception.

\section{Perceiving with the entire body}

Looking, hearing and even feeling one's own heartbeats cannot be easily separated from one another. As I transcribe the field notes after the ride, I still feel the leg muscles pulsating and my sweaty clothes emanating a sour smell. I listen to my voice on the recorder as it registers my heavy breathing and my disquiet reporting on the traffic noise. 
And I simultaneously watch the video footage offering a glimpse into my sustained effort to maintain balance amongst the many cars I encounter (Fieldnotes, Lancaster, 2016).

I started my account of cycling senses by describing the modus operandi of sight for cyclists, but this has been a contrivance. Such an artificial delimitation is part of an established Cartesian tradition that separates the body from the mind and, consequently, sensation from perception. This dualist ontology was challenged in the last century, with Merleau-Ponty's phenomenological philosophy (Merleau-Ponty 1962) and Gibson's ecological psychology (Gibson 1979) amongst the first to situate perception in relation to the whole body and the environment.

Gibson considers that the senses are engaged in what he calls a perceptual system which "can orient, explore, investigate, adjust, optimize, resonate, extract, and come to an equilibrium, whereas a sense cannot" (Gibson 1979, 244-245). Senses as perceptual systems facilitate an understanding of the cycling experience not simply as static responses of the mind to specific sensual stimuli registered by the body, but as an overlapping of active senses accounting for visual, aural, olfactory, tactile and other types of perceptual information which takes place as the cyclist pedals through the environment. Tim Ingold builds on Gibson's work and on other theories that regard perception as multisensory and insists that senses are not separated out at the point of perception. Instead, vision must be understood in its interrelation with other senses: "the eyes and ears should not be understood as separate keyboards for the registration of sensation but as organs of the body as a whole, in whose movement, within an environment, the activity of perception consists" (Ingold 2000, 268).

While Gibson and Ingold limit their discussion of the perceptual system to vision and hearing, I argue that of particular importance are the sensory modes unveiling the internal world of the cyclist: the sense of pain, the sense of our muscles and organs, the sense of balance, movement and temperature. Cycling involves a total sensuous experience,

where the visual field expanding ahead of my bicycle is complemented by a deafening roaring of traffic, the tactile experience of the wind blowing in my face and the sweat trickling on my abdomen, the mild pain in my legs as I accelerate when the green light turns on, the intimate sense of balance that I could lose at any time when a heavy truck passes me by and the nauseating smell of exhaust gas, all these attended at all times by a tiresome back pain from an old bike accident. They all blend into a total sensuous experience where the whole is bigger than the sum of its constitutive parts and where the experience of one sense cannot be effectively separated from others. (Field notes, London, 2015)

Highlighting the multisensory perception in cycling becomes particularly relevant when considering how traffic laws are drafted, what kind of cycling provisions are put in place, or how negative perceptions towards cyclists are articulated. For instance, going back to my admission of running red lights at the beginning of the analysis, a more nuanced understanding of this unlawful practice is possible. Acknowledging that cycling is constituted, experienced, understood, evaluated and maintained through all the senses, including, in this particular case, through the sense of balance or that of temperature, is essential. ${ }^{2}$

Thus, rather than considering those disobeying traffic rules as merely reckless cyclists, a different approach to building infrastructure and delivering road regulations could be proposed. Such reappraisals are already taking place in cities where cycling tends to be prioritised. For example, new regulations are allowing cyclists to run red lights in Paris 
(Van Mead 2015), while traffic lights are turning green for cyclists when it rains in Denmark (Merit 2016).

\section{Balancing the world by bike}

I have hardly left the house this morning and I am already stuck in traffic. As I make my way towards Aldgate East station, I weave through stopped cars, a delicate procedure which requires good bike handling skills and balance. Sometimes even this weaving is difficult, as there are almost no gaps to take advantage of. I place my hands on the brakes levers, narrow my shoulders, hold my breath and feel my heartbeats accelerating as I squeeze the elbows into the ribs to facilitate my intrusion. I have less than half a meter of space to move between a double decker and a minivan, so my equilibrium had to be perfect, a mere twitch to the left or right could get me into serious troubles. (Field notes, London, 2015)

Most cyclists lack the capacity to keep their balance and navigate through such narrow stretches. Yet, they are required to use a hand to signal a turn or to ride without too much wobbling (the so-called "dynamic envelope" of a cyclist should not take more than $1 \mathrm{~m}$ in width, as specified, for example, by the guidance for Cycle Infrastructure Design in the UK, published by the Department for Transport 2008). The sense of balance is not only interrelated with the other senses in the process of perception. Additionally, as the field notes above demonstrate, balance plays an essential role, alongside the rest of the senses, in shaping cyclists' spatial experience.

Arguing for the essential role of the context of perception in structuring the stimulation received by the senses, Gibson also coined the term "affordances". Affordances imply a complementarity between the subject and the environment, it "is neither an objective property nor a subjective property [...]. [lt] cuts across the dichotomy of subjectiveobjective [...]. It is equally a fact of the environment and a fact of behavior" (1979, 127-129). Unlike most other mobilities technologies, the bicycle dictates a series of affordances in relation to the body. Examples of such affordances are a fast bicycle cycled downhill allowing for an acceleration of one's heartbeats. Similarly, a wavering bicycle climbed up a hill or rushed through the London fast traffic, "affords" short and intense bursts of pain in the calves and sweat dripping off the temples. While a bicycle slowing down reveals an embodied sensorimotor practice of balance taken for granted until then.

Influenced by Gibson's ecological theory of perception, Rodaway (1994) advocates for "sensuous geographies" in an attempt to elicit interest in the sensuousness of the world. By understanding senses as relational to the environment, Roadway sought "to offer a more integrated view of the role of the senses in geographical understanding: the sense both as a relationship to a world and the senses as themselves a kind of structuring of space and defining of place" (1994, 4; emphasis in original).

The ways in which senses engage cyclists in a relationship to the world deserves a closer inspection since, as demonstrated so far throughout this article, the affordances available to cyclists can hardly be understood as simply a complementarity between the subject and the environment. On the contrary, the hostile road environments where cycling occurs alters and reconfigures the work of senses. It has been already indicated how cyclists' vision needs to adapt to anticipate the dangers posed by a left-turning car by checking its front wheels, how hearing is retrained to distinguish a menacing sound of 
a car ready to overtake and how such dangers engage, in turn, perceptible emotional responses.

In their investigation of commuter cycling, Jones (2012) similarly describes the "affective challenges" of riding a bicycle in Birmingham, while Simpson (2017) recalls both its positive and negative atmospheres. Other authors have used the notion of the "visceral" to explore further the intensity of sensory experiences and to connect them to the realm of political and power relations. In their work on the visceral nature of food experiences, Hayes-Conroy and Hayes-Conroy (2008) link the politics of everyday life with how the everyday is effectively practiced and experienced. Their argument is that the sensory experience of food represents a means to understand how power relations are embedded in everyday life. Rather than advocating "a move towards individualistic forms of beingpolitical", Hayes-Conroy and Hayes-Conroy propose "a radically relational view of the world, in which structural modes of critique are brought together with an appreciation of chaotic, unstructured ways in which bodily intensities unfold in the production of everyday life" $(2008,426)$.

This paper proposes a different approach to conceptualise the visceral nature of cycling senses. Yet, it is one which similarly aims to reveal the inequalities and exclusions embedded in everyday mobilities. In doing so, it draws on Lefebvre's (2004) rhythmanalysis to investigate the temporalities of urban movement and to distinguish between the mechanical and dominant rhythms of automobility and the more organic and subversive rhythms of cycling. The concept of rhythmanalysis is used here to bridge the multisensory experience of cycling to the broader atmospheres and ambiances of urban mobilities. In apprehending the world from the saddle, the body, the senses and the bicycle form a fluid hybrid of muscles, tendons, cranks and chain. Their effective coalescence gives the cycling experience a particular momentum which can be better described as "getting into a rhythm". Yet, since urban cycling unfolds in an environment where other mobilities also take place, this rhythm is necessarily interpellated by other rhythms, more or less similar. Their dialogue represents the focus of the next section.

\section{Achieving eurhythmia}

During my commute, I don't like to stop too often, in fact I frequently challenge myself: Can I ride the six kilometres to the university without laying the feet on the ground? When the traffic is sparse or when the green lights are perfectly aligned it works and I experience an achievement, but most often it doesn't. Knowing how and when to slow down, gently squeezing the brake levers while anticipating the obstacles well in advance, changing the gears in time for a climbing, for a descent or just to accommodate a rolling speed or keeping the toes glued to the pedals for as long as possible are expressions of a rhythm that, almost unconsciously, I look for as I cycle (Field notes, Lancaster, 2016).

The very different, yet effective, operation of the cyclists' senses so far described produces a distinctive cycling rhythm, which is unparalleled by that of other forms of transportation. Lefebvre has famously said that: "Everywhere where there is interaction between a place, time and an expenditure of energy, there is rhythm" (2004, 15). The French urbanist argues that the production of space can only be understood through rhythms. The everyday world is produced, he says, through repetition in time and space. Cycling, as a practice, is inhabited through rhythm and the co-ordination of various cycling rhythms 
to that of the cyclist's body is productive of meaning. Lefebvre's theorization of harmonized, disharmonized, organic and hierarchical rhythms can help illuminate both how effectively the cyclist's body is attuned to the world in the current car-dominated environments and how this could be different.

Lefebvre also insists on the centrality of the body in experiencing rhythms. According to him, the body should be understood as "a bundle of rhythms, different but in tune ... the body produces a garland of rhythms, one could say a bouquet" $(2004,20)$. Bodily rhythms function at their own paces (they are polyrhythmic) and at the same time they are coordinated (eurhythmic). Lefebvre argues that the space of the body is also the space of others: for the cyclist, the bodily bouquet of organic rhythms is engaged with the more mechanical rhythms of the bicycle as well as with those of the broader mobile order of which cyclists are a part.

Lefebvre defines rhythmanalysis as the project of appropriating the body as a spatial practice and the consequent desire to attain eurhythmia. This article has shown that sometimes the assemblage of bodies and bicycles can achieve such eurhythmia, the bicycle can be embodied by the skilful cyclist: knowing how to rise from the saddle to absorb the shocks from a pothole, leaning with the bicycle to negotiate a sharp bend, changing the gears for an ascent or a descent. Yet, sometimes the body and the bicycle are in arrhythmia, a destructive rhythm, discovered in the case of disease or dysfunction. When one is tired, or new to cycling, the bicycle or the body simply will "not listen". Full and deep breathing means the rhythm is there, whereas quick and shallow breathing is a sign of arrhythmia. Clogged ears, accelerated heartbeats, even sweating can be similar indicators of being out of rhythm.

Thus, the rhythm in cycling is as much about skill in handling the bicycle as it is about synchronisation, or lack thereof, with the rhythms of other mobilities. In this context, the opposite of eurhythmia, which is arrhythmia, becomes even more visible. Lefebvre understands eurhythmia as ethically superior to arrhythmia and even more so to isorhythmia, which he describes as a collection of hierarchically coordinated rhythms. Such rhythms are synchronized from above, being brought into occurrence by an exterior agent. This isorhythmia is particularly visible today in the urban realm, dominated by the mechanical rhythm of automobility. Not only does this synchronization take place from above, in the form of traffic rules and signs, but it also places any other non-motorized rhythms into arrhythmia, they become "abnormal" rhythms.

Through the analysis of rhythms, the multiple temporalities of places and forms of mobility are made explicit, argues Edensor (2014), who notes nevertheless that there exists "a series of different-paced and orchestrated mobile rhythms [that] produces a collectively constituted choreography that gives temporal shape to place" (2014, 163-164). But Edensor does not acknowledge that some of these mobility rhythms subvert others and that an arrhythmia is visible when the hybrid rhythms of cycling (or the organic rhythms of walking, for that matter) interfere with the mechanical rhythms of automobility. ${ }^{3}$ Today, the choreography of urban mobilities is significantly dictated by the mechanized rhythms of automobility, notices Spinney, as "the spaces, timings and hence rhythms of the road network ... reflect a bias towards functionalism but also towards motorised vehicles" (2010, 113).

Some cyclists have responded to such challenges by improvising their own rhythms (Spinney 2010; see also Latham and Wood 2015; Van Duppen and Spierings 2013), 
something that I have also demonstrated through my own decision to run red lights. There are also other "improvisations" says Spinney (2010), such as filtering through queuing traffic or avoiding the one-way system by riding on the pavement. Often these improvisations necessitate breaking the current traffic rules and establishing a different interaction order (Goffman 1983), where cyclists demonstrate informal rather than formal understandings of the traffic order and consequently use techniques of "negotiation in motion" (Jensen 2010) unmatched by other urban mobilities. A similar improvisation was part of my everyday commute to campus, where I had to negotiate a one-way system just before arriving at the office (see Figure 2):

Most of the time I turn left on Bowland Avenue North, even if I get to cycle against the sparse traffic. The alternative and legal route is just a few hundred meters down the road, via Bowland Avenue South, parallel to this one. I get to see cars coming towards me, so I am comfortable riding there, since that stretch is very short, there is enough room for incoming car to pass by and I am also eager to leave the busy North West Drive. Most drivers don't complain about the shortcut I'm taking, but once somebody yelled at me that I was not supposed to be there! (Field notes, Lancaster, 2016).

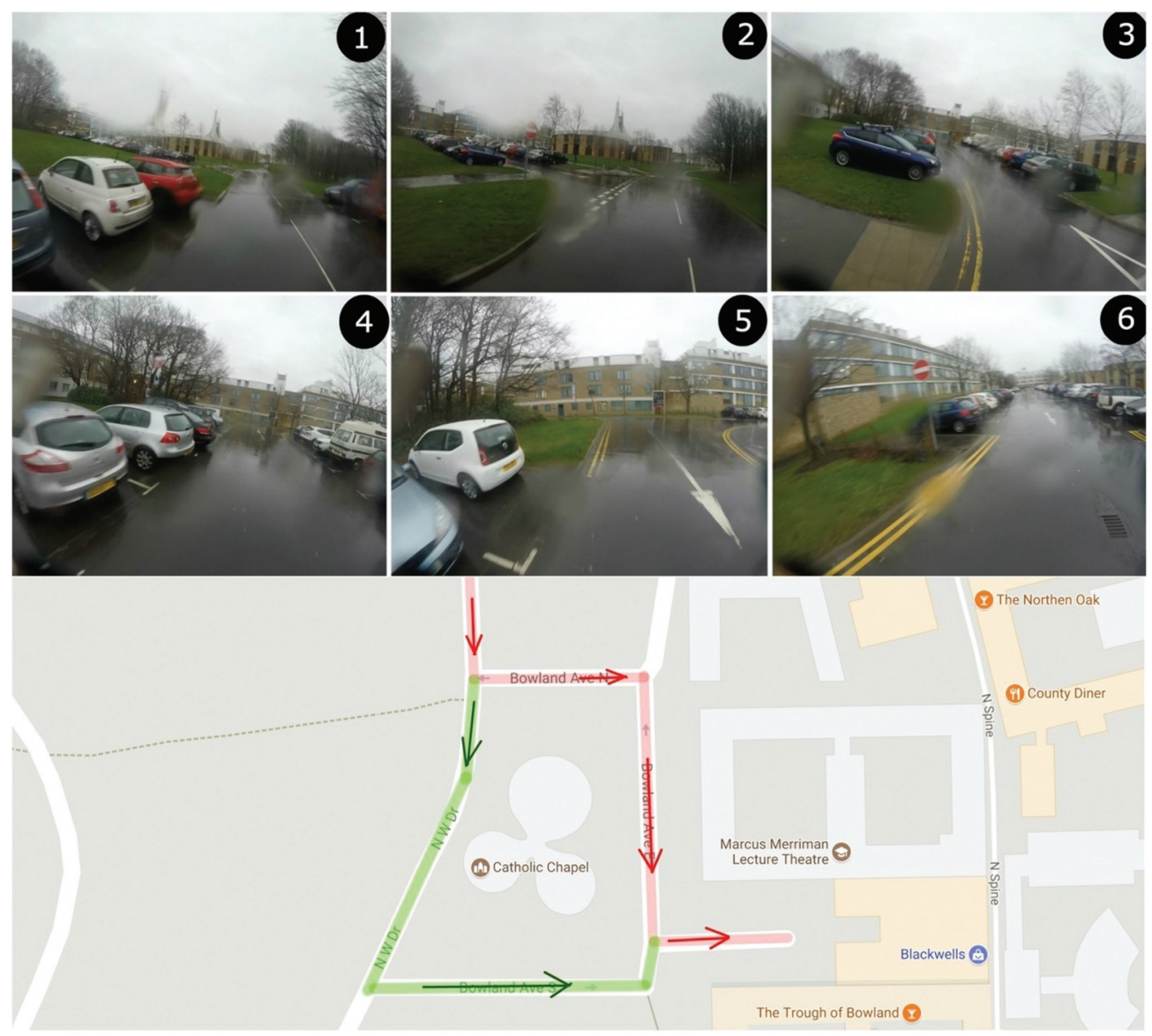

Figure 2. Negotiating a one-way system. On the map (Google Maps), I have highlighted the legal route with green, while the one I am following is in red (Lancaster, 2016). 
Through this improvisation, I effectively maintained the eurhythmia of my own cycling against the isorhythmia that is imposed through the car traffic regulations and infrastructures. While such a one-way system proves to be effective for car drivers, who would otherwise not be able to share the narrow road, the road configuration is certainly not beneficial for cyclists. And while drivers can easily maintain and sustain their mechanical rhythms, cyclists would be instead subordinated to the dominant rhythm, having to both do an unnecessary detour and stay for a longer period on a busier road.

Cycling inhabits an organic rhythm rather than a mechanical one, its practitioners deploying what de Certeau (1984) has described as marginal tactics, to oppose the dominant strategy of everyday life. Fragile and dependent on its own environment, the bicycle and cycling are decidedly situated on the side of tactics, on the side of the avoidance, of the adaptation to circumstances, but also on the side of the appropriation of space and time and the development of varied social practices. In opposition, the cars, sustained by their transport, industrial and energy infrastructures, are essentially strategic, as they organize and structure the space, as they modify it to their own advantage, by erasing all specificities.

\section{Conclusions}

By exploring the multisensorial nature of cycling, this paper has sought to problematise the utilitarian framing of urban movement, arguing that the future of sustainable mobilities cannot be envisioned without attending to its embodied aspects. For this purpose, the paper has focused less on the rather straightforward sustainability potential of cycling and has been instead more concerned with the sustainability of cycling itself as an alternative mobility. It argues that cycling has a sustainable future only to the extent that the practice is fully appreciated in policy and planning not merely from instrumental perspectives, but also as sensuous and affective mobility, that both attracts and deters its (non)participants. What this sustainability means in practice is that cycling can only broaden its appeal while also including a greater diversity of users if policies and infrastructures are designed with a view to address a broad variety of physical capabilities. Only the cities that cater for the cycling needs of an 8 year old and an 80 year old, of men and women alike, of the frail and the disabled, are sustainable cycling cities. Acknowledging cycling mobility as the entanglement of movement, representation, and indeed embodied practice (Cresswell 2010), rather than seamless transfer from $A$ to $B$, is thus an essential step to building sustainable cycling futures.

Equally, for a more sustainable cycling future to materialise, more eurhythmic, and even arrhythmic, mobilities need to emerge as challenges to the isorhythmia inflicted by the car system. Within the current system of automobility (Urry 2004), where all forms of mobility are subordinated to car driving, achieving eurhythmia appears impossible. The dominance exerted by automobility upon other urban mobilities perpetuates instead an isorhythmia whereby all mobility rhythms are dictated by the former. In this paper, I have identified such rare instances when the polyrhythmia of bodies, bicycles and urban mobilities is coordinated into a harmonious project. In such occasions, the bicycle becomes one with the cyclist and the road, a hybrid that is seamlessly gliding alongside an urban traffic no longer dominated by the automobile. Scanning eyes and trustworthy ears, subtle equilibrium and flashing pain coalesce to engage the cycling body with the world. In other instances, arrhythmia is instead visible, when body, bike and environment 
are not perfectly synchronised. In such circumstances, more cycle practice involving muscle strengthening and skill acquisition are generally enough to balance the bodily and mechanical rhythms.

Once this resistance, equally mounted by bodies, pedalling machines and hostile mobile environments is overcome, cycling is like a flow, where "action follows upon action according to an internal logic Once this resistanceseems to need no conscious intervention by the actor" (Csikszentmihalyi 1975, 10). The cycling action is experienced as "a unified field flowing from one moment to the next, in which he (sic!) is in control of his actions, and in which there is little distinction between stimulus and response, or between past, present and future" $(1975,10)$. Descriptions of mundane "cycling choreographies" (Colville-Andersen et al. 2013) at busy intersections in Copenhagen, where the less rulebound velomobilities are the norm, or glimpses into the "rolling continuity of cycling" (Brown 2012) within practices of mountain biking, are indications that such cycling flows already exist around us.

The motor car is here to stay, despite several claims in the last decade that a "peak car" has arrived. A consistent body of literature has emphasised a decline in car ownership, at least in the Western World, while also mapping many of the negative consequences of automobility: pollution, congestion, traffic deaths, energy consumption, climate change and social inequalities (Humes 2016; Newman and Kenworthy 2015; Whitelegg 2015; Ross 2014; Montgomery 2013). Yet, the car seems to have a bright future, which is increasingly electrified, shared, and autonomous (Popan 2019). With these technological changes, there are significant impacts on how urban mobilities will be sensed in the future. Against this backdrop, this paper has explored the possibility of sustainable cycling futures by investigating how the perception of the natural and social world is different by bicycle and how this could generate different meanings for what it means to "be-in-the-world". Unlike driving, which impoverishes the senses (Urry 2004), ${ }^{4}$ cycling promises an affordance that the system of automobility is unlikely to match: engaging the body with the environment, as opposed to disengaging it.

By investigating the operation of cycling senses, their relational character and the affordances generated by both the bicycle and the road environments, I have proposed a different understanding of mobility urban rhythms. This approach, pleading for the reintroduction of the embodied, the fleeting, the ephemeral, the emergent and the emplaced (Sheller and Urry 2006), often obliterated within the traditional quantitative and qualitative methods, can successfully complement the "quantified" research practices described at the beginning of this paper, which still dominate the investigation of most cycling practices. Equally important, by attending to the specificity of cycling senses and rhythms, new imaginaries can emerge in relation to how cities could plan and design for the sustainability of everyday mobile encounters.

\section{Notes}

1. See, amongst others, mass cycling events such as Ride London, the worldwide Critical Mass rides or mass media actions such as The Times' "Cities fit for Cycling Campaign", the now established "cycling section" in The Guardian or the Copenhagenize Bicycle-friendly Cities Index.

2. As a critical point, the heightened senses of balance and temperature are particular to fast cycle commuters, rather than the general cycling populace. This observation has critical 
implications for the design of future cycling systems, which should accommodate cyclists of all capabilities and skills.

3. Such arrhythmia and its problems are removed (or at least changed) when cycle-space is added to road-space.

4. This impoverishment is less visible in certain types of cars: sport convertibles, cars that still offer a manual transmission, cars that are not driverless.

\section{Disclosure statement}

No potential conflict of interest was reported by the author.

\section{Funding}

This work was supported by the Engineering and Physical Sciences Research Council [EP/J017698/1].

\section{ORCID}

Cosmin Popan (D) http://orcid.org/0000-0002-7877-1652

\section{References}

Aldred, R., and K. Jungnickel. 2012. “Constructing Mobile Places between 'Leisure' and 'Transport': A Case Study of Two Group Cycle Rides." Sociology 46 (3): 523-539. doi:10.1177/0038038511428752.

Borden, I. 2001. Skateboarding, Space and the City: Architecture and the Body. London: Berg Publishers.

Brown, K. M. 2012. "Sharing Public Space across Difference: Attunement and the Contested Burdens of Choreographing Encounter." Social \& Cultural Geography 13 (7): 801-820. doi:10.1080/ 14649365.2012.728614.

Büscher, M., J. Urry, K. Witchger, E. Laurier, and J. Gillen, eds. 2011. Mobile Methods. London New York: Routledge, Taylor \& Francis Group.

Certeau, M. D. 1984. The Practice of Everyday Life. Berkeley, California: University of California Press.

Colville-Andersen, M., P. Madruga, R. Kujanpää, and K. Maddox. 2013. "The Bicycle Choreography of an Urban Intersection". http://www.fietsberaad.nl/library/repository/bestanden/Bicycle_ Choreography_Copenhagenize.pdf

Conley, J. 2012. "A Sociology of Traffic: Driving, Cycling, Walking." In Technologies of Mobility in the Americas, edited by P. Vannini, L. Budd, O. Jensen, C. Fisker, and P. Jirón, 208-236. Bern, Switzerland: Peter Lang.

Cook, S., J. Shaw, and P. Simpson. 2016. "Jography: Exploring Meanings, Experiences and Spatialities of Recreational Road-Running." Mobilities 11 (5): 744-769. doi:10.1080/17450101.2015.1034455.

Cresswell, T. 2010. "Towards a Politics of Mobility." Environment and Planning. D, Society \& Space 28 (1): 17-31. doi:10.1068/d11407.

Csikszentmihalyi, M. 1975. Beyond Boredom and Anxiety: Experiencing Flow in Work and Play. London: Jossey-Bass.

Debord, Guy. 1981. 'Situationist Theses on Traffic'. In Situationist International Anthology, edited by Ken Knabb. Berkeley: Bureau of Public Secrets.

Department for Transport. 2008. "Cycle Infrastructure Design (LTN 2/08)." https://assets.publishing. service.gov.uk/government/uploads/system/uploads/attachment_data/file/329150/Itn-2-08_ Cycle_infrastructure_design.pdf

Department for Transport. 2017. "Cycling and Walking Investment Strategy." https://assets.publish ing.service.gov.uk/government/uploads/system/uploads/attachment_data/file/603527/cyclingwalking-investment-strategy.pdf 
ECF. 2017. "EU Cycling Strategy." Recommendations for Delivering Green Growth and an Effective Mobility System in 2030'. https://ecf.com/sites/ecf.com/files/EUCS_full_doc_small_file.pdf

Edensor, T. 2000. "Walking in the British Countryside: Reflexivity, Embodied Practices and Ways to Escape." Body \& Society 6 (3-4): 81-106. doi:10.1177/1357034X00006003005.

Edensor, T. 2014. "Rhythm and Arrythmia." In The Routledge Handbook of Mobilities, edited by P. Adey, D. Bissell, K. Hannam, P. Merriman, and M. Sheller, 163-171. London and New York: Routledge.

Featherstone, M. 2010. "Body, Image and Affect in Consumer Culture." Body \& Society 16 (1): 193-221. doi:10.1177/1357034X09354357.

Gibson, J. J. 1979. Ecological Approach to Visual Perception. New York and Hove: Psychology Press.

Goffman, E. 1963. Behavior in Public Places: Notes on the Social Organization of Gatherings. New York, NY: Free Press.

Goffman, E. 1983. "The Interaction Order: American Sociological Association, 1982 Presidential Address." American Sociological Review 48 (1): 1-17. doi:10.2307/2095141.

Grasseni, Cristina. 2007. 'Introduction'. In Skilled Visions: Between Apprenticeship and Standards, edited by Cristina Grasseni, 1-19. Oxford: Bergham.http://www.berghahnbooks.com/title/ GrasseniSkilled

Grous, A. 2011. "The British Cycling Economy: "Gross Cycling Product" Report." http://eprints.Ise.ac.uk/ 38063/

Hayes-Conroy, A., and J. Hayes-Conroy. 2008. "Taking Back Taste: Feminism, Food and Visceral Politics." Gender, Place \& Culture 15 (5): 461-473. doi:10.1080/09663690802300803.

Hopkins, S. 2015. "'Self-Righteous" Cyclists' With Helmet Cams Blamed For Road Rage'." HuffPost UK. Accessed 29 August 2015. http://www.huffingtonpost.co.uk/2015/08/29/cyclists-with-helmetcams-blamed-for-inflaming-road-rage-incidents_n_8042730.html

Humes, E. 2016. Door to Door: The Magnificent, Maddening, Mysterious World of Transportation. New York, NY: Harper.

Ingold, T. 2000. The Perception of the Environment: Essays on Livelihood, Dwelling and Skill. London: Routledge.

Ingold, T. 2004. "Culture on the Ground: The World Perceived through the Feet." Journal of Material Culture 9 (3): 315-340. doi:10.1177/1359183504046896.

Jacobs, J. 1961. The Death and Life of Great American Cities. New York: Vintage.

Jarrett, J., J. James Woodcock, U. K. Griffiths, Z. Chalabi, P. Edwards, A. I. Roberts, and A. Haines. 2012. "Effect of Increasing Active Travel in Urban England and Wales on Costs to the National Health Service." The Lancet 379 (9832): 2198-2205. doi:10.1016/S0140-6736(12)60766-1.

Jensen, O. B. 2010. "Erving Goffman and Everyday Life Mobility." In The Contemporary Goffman, edited by M. H. Jacobsen, 333-351. New York: Routledge.

Jones, P. 2005. "Performing the City: A Body and A Bicycle Take on Birmingham, UK." Social \& Cultural Geography 6 (6): 813-830. doi:10.1080/14649360500353046.

Jones, P. 2012. "Sensory Indiscipline and Affect: A Study of Commuter Cycling." Social \& Cultural Geography 13 (6): 645-658. doi:10.1080/14649365.2012.713505.

LaBelle, B. 2010. Acoustic Territories: Sound Culture and Everyday Life. New York: Continuum.

Larsen, J. 2014. "(Auto)ethnography and Cycling." International Journal of Social Research Methodology 17 (1): 59-71. doi:10.1080/13645579.2014.854015.

Latham, A., and P. R. H. Wood. 2015. "Inhabiting Infrastructure: Exploring the Interactional Spaces of Urban Cycling." Environment \& Planning A 47 (2): 300-319. doi:10.1068/a140049p.

Lefebvre, H. 2004. Rhythmanalysis: Space, Time and Everyday Life. London: Continuum.

Merchant, S. 2011. "The Body and the Senses: Visual Methods, Videography and the Submarine Sensorium." Body \& Society 17 (1): 53-72. doi:10.1177/1357034X10394670.

Merit, M. T. 2016. "Rain Makes the Light Go Green for Cyclists in the Danish City of Odense." Cycling Embassy of Denmark (blog). Accessed 10 May 2016. http://www.cycling-embassy.dk/2016/05/10/ rain-means-green-light-cyclists-danish-city-odense/

Merleau-Ponty, M. 1962. Phenomenology of Perception. London; New York: Routledge.

Middleton, J. 2010. "Sense and the City: Exploring the Embodied Geographies of Urban Walking." Social \& Cultural Geography 11 (6): 575-596. doi:10.1080/14649365.2010.497913.

Montgomery, C. 2013. Happy City: Transforming Our Lives Through Urban Design. London: Penguin. 
Muncey, T. 2010. Creating Autoethnographies. 1 ed. Los Angeles; London: SAGE Publications.

Newman, P., and J. R. Kenworthy. 2015. The End of Automobile Dependence: How Cities are Moving beyond Car-Based Planning. 2nd None ed. Washington, DC: Island Press.

Pink, S. 2009. Doing Sensory Ethnography. 1 ed. Los Angeles, Calif.: SAGE Publications.

Popan, C. 2019. Bicycle Utopias: Imagining Fast and Slow Cycling Futures. 1 ed. S.I.: Routledge.

Rodaway, P. 1994. Sensuous Geographies: Body, Sense and Place. London: Routledge.

Ross, B. 2014. Dead End. Oxford University Press.

Sennett, R. 1992. The Conscience of the Eye: The Design and Social Life of Cities. New York, NY: W. W. Norton \& Company.

Sennett, R. 2008. The Uses of Disorder: Personal Identity and City Life. UK New Haven: Yale University Press UK SR.

Sheller, M., and J. Urry. 2006. "The New Mobilities Paradigm." Environment and Planning A: Economy and Space 38 (2): 207-226. doi:10.1068/a37268.

Shove, E., M. Pantzar, and M. Watson. 2012. The Dynamics of Social Practice. Everyday Life and How It Changes. London: Sage.

Simpson, P. 2017. "A Sense of the Cycling Environment: Felt Experiences of Infrastructure and Atmospheres." Environment and Planning A: Economy and Space 49 (2): 426-447.

Spinney, J. 2006. "A Place of Sense: A Kinaesthetic Ethnography of Cyclists on Mont Ventoux." Environment and Planning. D, Society \& Space 24 (5): 709-732. doi:10.1068/d66j.

Spinney, J. 2007. "Cycling the City: Non-Place and the Sensory Construction of Meaning in a Mobile Practice." In Cycling and Society, edited by D. Horton, P. Rosen, and P. Cox, 25-46. Aldershot: Ashgate.

Spinney, J. 2009. "Cycling the City: Movement, Meaning and Method." Geography Compass 3 (2): 817-835. doi:10.1111/j.1749-8198.2008.00211.x.

Spinney, J. 2010. "Improvising Rhythms: Re-Reading Urban Time and Space through Everyday Practices of Cycling." In Geographies of Rhythm: Nature, Place, Mobilities and Bodies, edited by T. Edensor, 113-128. Burlington, VT: Ashgate.

Spinney, J. 2011. "A Chance to Catch A Breath: Using Mobile Video Ethnography in Cycling Research." Mobilities 6 (2): 161-182. doi:10.1080/17450101.2011.552771.

Tonkiss, F. 2003. "Aural Postcards. Sound, Memory and the City." In The Auditory Culture Reader, edited by M. Bull and L. Back, 303-310. Oxford, UK: Berg.

Transport for London. 2008. "Cycling in London." http://content.tfl.gov.uk/cycling-in-london-finaloctober-2008.pdf

Transport for London. 2013. "The Mayor's Vision for Cycling in London. An Olympic Legacy for All Londoners." https://www.london.gov.uk/sites/default/files/cycling_vision_gla_template_final.pdf

Urry, J. 2004. "The 'System' of Automobility." Theory, Culture \& Society 21 (4-5): 25-39. doi:10.1177/ 0263276404046059.

Van Duppen, J., and B. Spierings. 2013. "Retracing Trajectories: The Embodied Experience of Cycling, Urban Sensescapes and the Commute between 'Neighbourhood'and 'City'in Utrecht, NL." Journal of Transport Geography 30: 234-243.

Van Mead, N. 2015. "Should Cyclists Be Allowed to Run Red Lights?" The Guardian, Accessed 27 October 2015, https://www.theguardian.com/cities/2015/oct/27/cyclists-run-red-lights-parislondon-san-francisco

Vine, S. 2015. "Cycling Stasi: Never Mind Drivers Eating Cereal. SARAH VINE Says the Real Menaces on Our Roads are Vigilantes in Lycra Filming Your Every Move'. Mail Online." Accessed 19 June 2015. http://www.dailymail.co.uk/debate/article-3130690/SARAH-VINE-says-real-menaces-roadsvigilantes-Lycra-filming-move.html

Whitelegg, John. Mobility: A New Urban Design and Transport Planning Philosophy for a Sustainable Future. Church Stretton, UK: Straw Barnes Press, 2015.

WHO. 2017. "Health Economic Assessment Tool (HEAT) for Walking and for Cycling. Methods and User Guide on Physical Activity, Air Pollution, Injuries and Carbon Impact Assessments." http:// www.euro.who.int/_data/assets/pdf_file/0010/352963/Heat.pdf?ua=1 